\title{
Endogenous growth and intellectual property rights: a North-South modelling proposal with population ageing
}

\author{
MÓNICA L. AZEVEDO \\ Portucalense University \\ ÓSCAR AFONSO \\ University of Porto, Faculty of Economics \\ SANDRA T. SILVA \\ University of Porto, Faculty of Economics, and CEFUP
}

\begin{abstract}
This paper studies the effect of Intellectual Property Rights (IPR) on economic growth, in the light of population ageing, i.e., in a more realistic context. The analysis is motivated by the implications of population ageing on economic growth. Moreover, this study analyses this relationship in a North-South framework where there is a health-care sector. We conclude that population ageing has no impact on the sign of the IPR effect on economic growth. However, it positively affects the steady-state growth rate. Finally, under some conditions, the presence of the health-care sector also increases the steadystate growth rate.
\end{abstract}

Keywords: North-South model, endogenous growth, health-care sector, population ageing, IPR.

JEL-codes: I15, J10, O34, O41, O43

\section{Introduction}

Population ageing, especially in the most developed countries, has become an important factor in the economic and social debate. According to Prettner (2013) among others, this topic has been discussed both in academic approaches and in public forums (e.g., Bloom et al. 2008, 2010a, 2011; The Economist 2009, 2011).

In accordance with Nagarajan et al. (2013), although the increase in longevity and the decrease in mortality rates are important outcomes of advances in medical science, these two facts and the decrease in fertility rates can represent a serious economic problem, since they are synonymous with ageing populations in many developed 
(North) countries (e.g., Harper and Leeson, 2009). The diminution in population growth is also a reality in several countries and is mainly justified by the adult working-age population outstripping the child population (e.g., Mason and Lee, 2011).

Several works have studied the impact of ageing on economic growth (e.g., Lindh and Malmberg, 2009; Bloom et al., 2010b; Eiras and Niepelt, 2012; Prettner, 2013). Groezen et al. (2005) show that while in a closed country the effect of rising longevity on growth can rely on the substitutability of labour and capital, in a small open country ageing unequivocally leads to a decline in long-run growth. Bloom et al. (2010b) state that population ageing decreases labour force participation and saving rates; thus, concerns about an eventual reduction in economic growth associated with this phenomenon are increasing. Nevertheless, the authors conclude that this effect may only have a discrete impact regarding the decrease in the economic growth rate in OECD countries. They express the considered view that population ageing will not significantly inhibit the economic growth speed in developing (South) countries, which is not the case in non-OECD countries.

Narciso (2010) also finds a negative relationship between population ageing and economic growth, due to a decrease in the human-capital stock. Moreover, Eiras and Niepelt (2012), Lisenkova et al. (2012) and Walder and Döring (2012) support the negative (albeit indirectly) relationship between population ageing and economic growth. However, this negative relationship is not always affirmed. For example, Hazan and Zoabi (2006) show how health and longevity can play an important role in the transition process from stagnation to growth of a certain country. According to Lee et al. (2011), a positive effect of ageing on growth is possible when the share of the active working age population is higher than the non-working population's share (e.g., Cervellati and Sunde, 2005; Prettner, 2013).

Actually, the literature review made by Nagarajan et al. (2013) shows the effect of ageing in states' performance is closely associated with the mechanism chosen (consumption and savings patterns, human capital or pubic social expenditures).

Bearing in mind the increasingly importance of ageing effects on socioeconomic development as well as the importance of innovation to economic growth, we extend Azevedo et al. (2014) to address the impact of ageing (following Blanchard, 1985), on worldwide economic growth and, since both a North innovator country and a South imitator country are considered, to study whether this change has a significant impact on the effect of Intellectual Property Rights (IPR) on economic growth. 
Moreover, once introduced a more realistic context of population ageing, we have also introduced an additional sector: the health-care sector - in line with Kuhn and Prettner (2012). Then, a different setup from those present in the existing literature is used, namely where IPR are introduced. These differences are important because they allow us to state whether by introducing changes in the model's assumptions, the effect of IPR on economic growth is modified, and to verify if possible different results can be explained by differences in the model's setup.

Then, this paper aims to answer the following questions: What is the sign of the ageing impact on economic growth rate? Does the introduction of ageing population change the effect of IPR on economic growth rate? What is the impact of health care on economic growth rate?

In fact, besides the above considerations about the discussion of ageing effects on economy and society, IPR have emerged as an important field of study on economic growth. By protecting intellectual property, IPR protect innovation against imitation constituting an incentive to innovators. As innovation and technological-knowledge is considered to be crucial for economic growth (e.g., Romer, 1990; Aghion and Howitt, 1992; Hall and Rosenberg, 2010), the discussion of IPR plays an important role in the economic growth analysis (e.g. Park and Ginarte, 1997; Lai, 1998; Glass and Saggi, 2002; Falvey et al., 2006; Sener, 2006; Branstetter et al., 2007; Glass and Wu, 2007; Panagopoulos, 2009; Dinopoulos and Segerstrom, 2010).

The rest of the paper is structured as follows. After these introductory remarks, Section 2 presents the setup of the model, Section 3 analyses the equilibrium and Section 4 concludes.

\section{Setup of the model}

Mainly bearing in mind Azevedo et al. (2014) and Kuhn and Prettner (2012), we describe the fundamental considerations regarding the model's structure, emphasising the main differences: the changes introduced by considering ageing population and the additional health-care sector.

We introduce an overlapping generations structure in the spirit of Blanchard (1985) into a model similar to Romer's (1990), in which the R\&D investments are the main engine of endogenous economic growth. The economy is constituted by four sectors: final-goods sector, intermediate-goods sector, $R \& D$ sector and health-care sector. The intermediate-goods sector produces under conditions of monopolistic 
competition, while the others operate under perfect competition. Moreover, there is perfect labour mobility between the final-goods and the health-care sectors.

In relation to demographic properties, we consider, a stationary population (such as that in Romer's (1990) model), which is comprised of several groups of people, identified by their date of birth, $t_{0}$. Hence, we assume that the birth rate (being comparable to the period fertility rate in a certain context) is equal to the mortality rate, $\mu$. At a given moment $t>t_{0}$, each of these cohorts is composed of a number of $N\left(t_{0}, t\right)$ agents. We consider that these agents face a constant risk of death at each instant, $\mu$, which equals the fraction of the population dying at each moment due to the law of large numbers (e.g., Blanchard, 1985; Kuhn and Prettner, 2012).

Additionally, although we assume that increases in the health-care level lead to decreases in the mortality rate, which in turn means proportional decreases in the birth rate, this is not consistent with changes in fertility decisions, but only consistent with an 'accounting effect'. That is to say, as with Kuhn and Prettner (2012), we consider that for a constant cohort fertility rate, a reduction in mortality must lead to a one-to-one reduction in period fertility. Moreover, with rising longevity, agents extend a constant number of births through a longer lifespan, which implies, statistically, that there are fewer newborn children at each moment in time. Consequently, the birth rate is inferior. This is in line with the evidence, which suggests that the decrease in period fertility rates detected over the past several years cannot imply a decrease in cohort fertility, but can be caused by the postponement of fertility through a lifespan of increasing duration (e.g., Bongaarts and Sobotka, 2012).

\subsection{Consumers}

The Northern consumer makes consumption and saving decisions in order to maximize the present value lifetime (e.g., Prettner, 2013; Kuhn and Prettner, 2012):

$$
U=\int_{t_{0}}^{\infty} u\left(\bar{c}_{N}\right) e^{-\left(\rho+\mu_{N}\right)\left(m-t_{0}\right)} d m
$$

where,

$$
\begin{gathered}
u\left(\bar{c}_{N}\right)=\left(\frac{\bar{c}_{N}^{1-\theta}-1}{1-\theta}\right), \\
\bar{c}_{N}=c_{N}^{k} c_{S} f^{1-k} .
\end{gathered}
$$

s.t.

$$
\dot{a}_{N}=\left(r_{N}+\mu_{N}-\gamma\right) a_{N}+(1-\Gamma) w_{N} l_{N}+d_{N}-\operatorname{expend}_{N}-p_{H_{N}} \vartheta h_{N}
$$


where,

$$
\operatorname{expend}_{N}=P_{N} c_{N}+P_{S}^{f} c_{S}^{f} .
$$

Thus, we use a constant intertemporal elasticity of substitution (CIES) instantaneous utility function, $u\left(\bar{c}_{N}\right)$, where $\bar{c}_{N}$ denotes the Northern composite good, $\theta$ refers to the inverse intertemporal elasticity of substitution and $\rho>0$ represents the homogeneous subjective discount rate. Equation (3) is a Cobb-Douglas aggregator that defines the Northern composite good, $\bar{c}_{N}$, in terms of Northern and Southern final goods, $c_{N}$ and $c_{S}^{f}$, respectively, both consumed in the North ( $f$ means foreign or exports). In the same equation, parameter $k$ corresponds to domestic expenditure-share.

The set of expressions (1)-(5) presents the modified individual's lifetime utility and the modified budget constraint (the path of the value of assets) where $t_{0}$ corresponds to the date of birth of a given generational group and $\mu \geq 0$ is the mortality rate. This latter rate increases the discount rate of agents because individuals face the risk of death and, hence, they postpone consumption lesser than in the case of lifetime certainty. We assume that, within a given cohort, the wealth of dead agents is redistributed by those who have survived (e.g., Prettner, 2013). Thus, the real rate of return is increased by the mortality rate. We also consider that there is a tax on labour income similar to contributions for social security applied by the government. Below, when describing the health-care sector, we stress how the public share of health care is supported by this tax.

We also assume that, as far as the consumer's problem is concerned, the agents expend their earnings both on consumption and on private health care (e.g., Kuhn and Prettner, 2012). In the case of the wealth constraint - expression (4) $a$ denotes the individual assets stock, $r_{N}$ is the return of the assets and $\gamma \geq 0$ refers to the rate depreciation; $w l$ represents the agent's (yearly) wage income, where $w$ is the wage rate and $l$ is the agent's inelastic yearly labour supply (in a similar way to Papageorgiou, 2002, with human capital, we establish $l=l_{Y}+l_{H}$, where $l_{Y}$ and $l_{H}$ are the fractions of workers allocated to the production of the final good and to the health-care sector); $\Gamma \in$ $[0,1]$ denotes the tax on labour income; $d$ is the earnings from dividends (net of new

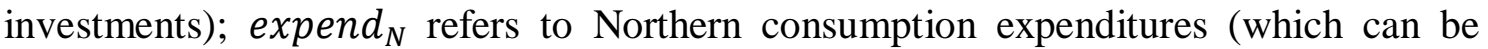
defined as $\operatorname{expend}_{N}=\bar{c}_{N} \bar{P}_{N}$ as is possible to deduce through the equations presented in Connolly and Valderrama, 2005); and $p_{H} \vartheta h$ represents the private health care 
payments, where $p_{H}$ is the unit price, $h$ denotes the total amount of health care and $\vartheta \in$ $[0,1]$ refers to the private finance share.

Solving the maximization problem, results the individual Euler equation:

$$
\frac{\dot{\bar{c}}_{N}}{\overline{\bar{c}}_{N}}=\hat{\bar{c}}_{N}=\frac{1}{\theta}\left(r_{N}-\gamma-\frac{\dot{\bar{P}}_{N}}{\overline{\bar{P}}_{N}}-\rho\right),
$$

which allows us to conclude that consumption only grows when the rate of return on assets outstrips the sum of the capital depreciation rate, the price growth and the subjective time discount rate.

In the South, the problem is symmetric.

\subsection{Aggregate capital stock and aggregate consumption}

The individual Euler equation in (6) is similar to the one that emerged in the case of no lifetime uncertainty (e.g., Azevedo et al., 2014). Nevertheless, now we assume not just a representative agent, but rather heterogeneous individuals relative to both age and wealth accumulation, because elderly people have had more time to accumulate positive capital. Next, we employ some aggregation rules (e.g., Prettner, 2013; Kuhn and Prettner, 2012; Heijdra and Ploeg, 2002) to obtain the Northern law of motion for the aggregate capital and the economy-wide ("aggregate") Euler equation:

$$
\begin{aligned}
& \mathcal{A}_{N}(t) \equiv \int_{-\infty}^{t} a_{N}\left(t_{0}, t\right) N_{N}\left(t_{0}, t\right) d t_{0}, \\
& \bar{C}_{N}(t) \equiv \int_{-\infty}^{t} \bar{c}_{N}\left(t_{0}, t\right) N_{N}\left(t_{0}, t\right) d t_{0},
\end{aligned}
$$

where $\mathcal{A}_{N}(t)$ refers to the Northern aggregate capital. Considering that, with a constant population, each generational group has the size $\mu_{N} N_{N} e^{\mu_{N}\left(t_{0}-t\right)}$ at a time $t>t_{0}$, and that at time $t$, total population size is given by $\int_{-\infty}^{t} \mu_{N} N_{N} e^{\mu_{N}\left(t_{0}-t\right)} d t_{0}$, we obtain:

$$
\begin{gathered}
\mathcal{A}_{N}(t) \equiv \mu_{N} N_{N} \int_{-\infty}^{t} a_{N}\left(t_{0}, t\right) e^{\mu_{N}\left(t_{0}-t\right)} d t_{0}, \\
\bar{C}_{N}(t) \equiv \mu_{N} N_{N} \int_{-\infty}^{t} \bar{c}_{N}\left(t_{0}, t\right) e^{\mu_{N}\left(t_{0}-t\right)} d t_{0} .
\end{gathered}
$$

After some mathematical operations, we arrive at the expressions for the Northern law of motion of the aggregate capital and for the Northern aggregate Euler equation (see Appendix and Kuhn and Prettner, 2012):

$$
\begin{gathered}
\dot{\mathcal{A}}_{N}=\left(r_{N}-\gamma\right) \mathcal{A}(t)-E_{N}(t)+(1-\Gamma) W_{N}(t)+D_{N}(t)-p_{H_{N}} \vartheta H_{N}, \\
\frac{\dot{\bar{C}}_{N}}{\overline{\bar{C}_{N}}}=\hat{\bar{C}}_{N}=\frac{1}{\theta}\left(r_{N}-\rho-\frac{\dot{\bar{P}}_{N}}{\bar{P}_{N}}-\gamma\right)-\mu_{N} \Lambda_{N},
\end{gathered}
$$


where $E_{N}(t), W_{N}(t), D_{N}(t)$ and $H_{N}$ refers to Northern aggregate expenditures, aggregate labour income, aggregate (net) dividends and aggregate health care consumption respectively; $\Lambda_{N}=\frac{\bar{C}_{N}(t)-\bar{C}_{N}(t, t)}{\bar{C}_{N}(t)} \in[0,1]$.

We can verify that the aggregate Euler equation differs from the individual Euler equation in the term $-\mu_{N} \frac{\bar{C}_{N}(t)-\bar{c}_{N}(t, t) N}{\bar{C}_{N}(t)} \in[-\mu, 0]$. As the consumption of the newborns, $\bar{C}_{N}(t, t)$, is lower than aggregate consumption, $\bar{C}_{N}(t)$, individual consumption growth will be higher than aggregate consumption growth. Indeed, at each moment, a proportion $\mu$ of elder and richer agents die, being substituted by poorer newborns. Since these individuals can barely afford consumption compared with the oldest, the aggregate consumption growth, as compared to individual consumption growth, is slowed by the replacement of generations (e.g., Heijdra and Ploeg, 2002). Moreover, with Kuhn and Prettner (2012), we assume that the term $\Lambda$, which can be written as

$$
\Lambda_{N}=\left(\rho+\mu_{N}\right) \frac{\mathcal{A}_{N}(t)}{\bar{C}_{N}(t) \bar{P}_{N}},
$$

is stable over time (Appendix), when the aggregate financial wealth, $\mathcal{A}_{N}(t)$, grows at the same rate as the total Northern consumption expenditures, $\bar{C}_{N}(t) \bar{P}_{N}=E_{N}(t)$.

\subsection{Health-care sector}

In this sector, health care is obtained from labour according to the following production function (e.g., Kuhn and Prettner, 2012):

$$
h N=L_{H},
$$

in which $h$ denotes the per capita health care, $N$ is the size of the population and $L_{H}$ represents aggregate employment in the health-care sector. Equivalently, we can write $h=\frac{L_{H}}{N}$, and can thus state that per capita consumption of health care increases when employment in this sector rises. Therefore, an upper bound on the consumption of health care per capita appears for the constraints $L_{H} \leq L \leq N$, where $L$ is the size of the available labour force: $h_{\max }=\frac{L}{N} \leq 1$. The idea behind the constraints is intuitive and easy to understand: the supply of health care cannot exceed a degree at which the health-care sector uses total labour force.

We also assume that the mortality rate diminishes at the per capita annual level of health care, $h$, and thus we write the mortality rate as $\mu(h)$. We consider:

$$
\mu(0)=\bar{\mu} \in(0, \infty), \mu\left(h_{\max }\right)=\underline{\mu} \in[0, \bar{\mu}),
$$




$$
\mu^{\prime} \leq 0, \mu^{\prime \prime} \geq 0, \mu^{\prime \prime \prime} \leq 0
$$

which suggests that, as a result of an increase in health care, the mortality rate can decrease from a maximum $\bar{\mu}$ to a minimum $\underline{\mu} \geq 0$. The minimum is achieved in the presence of the maximum attainable level of health care, $h_{\max }$, that is, when the healthcare sector uses total available labour. ${ }^{1}$ We also consider that health care is subject to diminishing returns, though in a fairly insignificant way. We assume that health care reduces not only the mortality rate, but also the rate of incidence of a disease, which enables agents to raise their annual effective labour supply, $l(h)$. In particular, we consider that:

$$
\begin{gathered}
0 \leq l(0) \leq l\left(h_{\max }\right)=h_{\max } \leq 1, \\
l^{\prime} \geq 0, l^{\prime \prime} \leq 0, l^{\prime \prime \prime} \geq 0 .
\end{gathered}
$$

That is, the supply of labour per capita rises in line with the degree of health care at weakly decreasing returns. Moreover, if we consider that agents provide the same quantity of labour in spite of their age (the mortality rate is independent of age), we can express the total supply of labour as: ${ }^{2}$

$$
L=l(h) N .
$$

Thus, the constraint $L_{H} \leq L \leq N$ entails $h \leq l(h) \leq l\left(h_{\max }\right)=h_{\max } \leq 1 .^{3}$

Another feature of this sector is the funding of health care. We consider $\vartheta \in[0,1]$ as the private finance share and $(1-\vartheta)$ as the public share, which is financed by a tax on labour income that is equivalent to a social security contribution (e.g., Kuhn and Prettner, 2012). Hence, the aggregate health expenditure, denoted by $G$, is given by

$$
w L_{H}=G=p_{H} \vartheta H+\Gamma W .
$$

The left hand side of (20) describes the health-care expenditure, $w L_{H}=w h N$. The right hand side presents the composition of funding, where $p_{H} \vartheta H=p_{H} \vartheta h N$ is the amount of private finance and $\Gamma W=\Gamma w l(h) N$ is the amount of public finance, the public health-care budget being balanced at each $t$. Since the health-care sector works under perfect competition, $p_{H}=w$, which allows us to rewrite (20) as $h=\vartheta h+\Gamma l(h)$, and since we can solve it for the tax rate, we obtain $\Gamma=\frac{(1-\vartheta) h}{l(h)} \in[0,1]$. Hence, the per

\footnotetext{
${ }^{1}$ Lichtenberg (2004) and Cutler et al. (2006), for example, empirically support the effect of health care on mortality or on longevity.

${ }^{2}$ At the aggregate level, we can denote $l(h)$ as the share of population that can work full time or as the average time at work, where agents may differ in their provision of labour, relying on whether or not they are healthy or ill (e.g., Kuhn and Prettner, 2012).

${ }^{3}$ If $l(h)$ is not a measure of participation, but of productivity, it is understandable that $l\left(h_{\max }\right)=h_{\max }>$

1. Kuhn and Prettner (2012), for example, ignore this case without loss of generality.
} 
capita supply of health care, $h$, and the public share, $(1-\vartheta)$, positively affect tax, while the per capita provision of labour has a negative impact. If we assume perfect competition and a non-distortionary tax, economic growth is not affected by the mode of health care funding; i.e. growth is determined by the size of the health-care sector, measured by $h$, but not by how health care is financed (e.g., Kuhn and Prettner, 2012).

\subsection{Final-goods sector}

We assume that the final good, $Y$, is produced under perfect competition and can be produced in the North and the South according to

$$
Y_{i}(t)=A_{i} L_{Y, i}^{\alpha} \sum_{j=1}^{J}\left(q^{k_{N}(j, t)} x_{i}(j, t)\right)^{1-\alpha}, i \in\{N, S\},
$$

where $A_{i}$ is an exogenous productivity level, which relies on the country's institutions (we consider that $A_{N}>A_{S}$ ); $L_{Y, i}$ denotes the labour input used in the final goods production and $\alpha \in[0,1]$ refers to the share of labour; $q^{k_{N}(j, t)} x_{i}(j, t)$ represents the quality adjusted intermediate good $j$ in time $t, q>1$ is a constant fixed exogenously, which expresses the size of each quality improvement reached by each successful R\&D activity, $k$ denotes the steps of the quality ladder (a higher quality is indicated by a higher $k), x_{i}(j, t)$ refers to the quantity of intermediate good used in the final good production; $(1-\alpha)$ is the aggregate factor share of the intermediate goods.

In both countries, given the price of the final good $i, p_{i}(t)$, and the price of the intermediate good $j, p(j, t)$, the implicit demand for each intermediate good by the representative final good producer is:

$$
x_{i}(j, t)=L_{Y_{i}}\left[A_{i}(1-\alpha) \frac{p_{i}(t)}{p(j, t)}\right]^{\frac{1}{\alpha}} q^{k_{N}(j, t)}\left[\frac{1-\alpha}{\alpha}\right] .
$$

Putting this expression into (21), replacing $p_{i}(t)$ by the marginal cost, $M C_{i}$, and $p(j, t)$ by the limit prices reported in the next subsection, the final goods supply in the North and in the South is, respectively:

$$
\begin{gathered}
Y_{N}(t)=A_{N}^{\frac{1}{\alpha}}\left(\frac{1-\alpha}{q}\right)^{\frac{1-\alpha}{\alpha}} L_{Y, N} Q_{N}\left[n_{N N}+n_{N S}\left(1+\tau_{x_{S}}\right)^{\frac{\alpha-1}{\alpha}} M C_{S}^{\frac{\alpha-1}{\alpha}}+n_{S} q^{\frac{1-\alpha}{\alpha}}\right], \\
Y_{S}(t)=A_{S}^{\frac{1}{\alpha}}\left(\frac{1-\alpha}{q}\right)^{\frac{1-\alpha}{\alpha}} L_{Y, S} Q_{N}\left[n_{N N}\left(\frac{M C_{S}}{1+\tau_{x_{S}}}\right)^{\frac{1-\alpha}{\alpha}}+n_{N S}\right. \\
\left.+n_{S} q^{\frac{1-\alpha}{\alpha}}\left(\frac{M C_{S}}{1+\tau_{x_{S}}}\right)^{\frac{1-\alpha}{\alpha}}\right]
\end{gathered}
$$




$$
Q_{N}=\sum_{j=1}^{J} q^{\frac{k_{N}(j, t)(1-\alpha)}{\alpha}}
$$

From the expressions above, we can verify that aggregate production in both economies depends on $Q_{N}$ (the Northern aggregate quality index), because the limit pricing with free trade ensures that only the highest technological knowledge will be used. Therefore, even in the case in which an intermediate good is produced in the North, its quality degree is the same as the top Northern quality level.

As the final good is produced under perfect competition, its price is equivalent to its marginal cost: The marginal cost of producing an intermediate good is independent of its stage of quality and is comparable among all internal sectors. Normalizing the Northern marginal cost to one of $\left(M C_{N}=1\right)$, we assume that $M C_{N}>M C_{S}$.

\subsection{Intermediate-goods sector}

The technological level and the trade barriers of each country define which one produces the intermediate goods used in the final-goods production (e.g., Azevedo et $a l ., 2014)$. Since the North is more advanced, it is expected to innovate, promoting a world technological-knowledge frontier. The South, by imitating Northern technological knowledge, can raise its domestic technological-knowledge level (this may occur until the gap is abolished). Moreover, we assume that when a country knows how to produce an intermediate good, it can be produced using the final goods production function. In this sense, the marginal cost of producing an intermediate good and that of producing the final good, $M C_{i}$, are equal, and by assuming that $0<M C_{S}<$ $M C_{N}=1$, the South can produce the same quality degree, $k$, but at a lower price. Thus, from a successful imitation, a Southern firm can capture the world market.

We also suppose that the technological knowledge of how to produce a good is domestically free and that the domestic IPR are protected. We thus focus on international IPR, which protect the innovator economy from foreign imitation. Henceforth, when we refer to IPR protection we mean international IPR protection.

Bearing in mind the demand equation (22), the profits of monopolist intermediate goods firms are maximized throughout the optimal price, given by the following markup (e.g., Azevedo et al., 2014):

$$
p(k, j, t)=p(j, t)=p=\frac{1}{1-\alpha},
$$

which is stable over time, across firms and for all quality levels. The mark-up is lower when $\alpha$ is nearer zero, and hence there is less opportunity for monopoly pricing. 
The expected profits are affected by how the firms compete. There are three types of firms: Northern firms challenging Northern competition, $n_{N N}$, Northern firms facing Southern competition, $n_{N S}$, and Southern imitation firms (which always face Northern competition), $n_{S}$. By assumption, there are $J$ sectors and the sum of these shares is equal to $J(=1)$. As each type of firm can have both national and international sales, we find six limit prices. Northern firms facing Northern rivalry fix a limit price slightly below $q$ times the lowest price at which the former innovator could sell, because the good is $q$ times more productive than the previous one. As $M C_{N}=1$ is the lowest price at which the precursor innovator could sell in the North and $\left(1+\tau_{x_{S}}\right)$ is the lowest price at which the good could be sold in the South, since it is subject to Southern tariffs and advalorem transportation costs, $\tau_{x_{S}}$, Northern firms challenging Northern competition, $n_{N N}$, select two limit prices: $P_{N N}=q M C_{N}=q$ for internal sales and $P_{N N}^{f}=q\left(1+\tau_{x_{S}}\right)$ for Southern sales. ${ }^{4}$ At these prices, world sales of all obsolete technologies will disappear. In the same way, Northern firms facing Southern competition, $n_{N S}$, choose limit prices $P_{N S}=q M C_{S}\left(1+\tau_{x_{S}}\right)$ for national sales and $P_{N S}^{f}=q M C_{S}$ internationally. Southern firms, $n_{S}$, always challenge Northern competition and fix limit prices $P_{S}^{f}=1$ for foreign countries and $P_{S}=1+\tau_{x_{S}}$ for national sales.

\section{6. $R \& D$ sector}

$\mathrm{R} \& \mathrm{D}$ firms choose the quantity of employed resources, according to the expected present value of profits from successful $R \& D$, which relies on the probabilities of innovation and imitation (e.g., Azevedo et al., 2014). Northern R\&D activities generate innovative blueprints for manufacturing intermediate goods, thus improving their quality. In an intermediate good $j$, presently at quality degree $k_{N}(j, t), I_{N}(j, t)$ denotes the probability that the $\left(k_{N}(j, t)+1\right)^{\text {th }}$ innovation will occur at time $t$ and will follow a Poisson process. IPR protect the designs domestically, and in each $j$, the top firm (the one producing according to the latest patent) applies limit pricing to ensure monopoly.

The probabilities of successful innovation and imitation are crucial, since they creatively remove either the existing lead design (e.g., Aghion and Howitt, 1992) or the Northern production (e.g., Grossman and Helpman, 1991, Ch. 12), thus affecting the monopoly duration. For simplicity, an important feature of our model is associated with

\footnotetext{
4 "This holds if $q(1-\alpha) \leq 1$. If instead, $q(1-\alpha)>1$, then Northern firms will use monopoly pricing" (Connolly and Valderrama, 2005, pp. 13).
} 
R\&D technology: we assume that there is a positive effect of a healthy population on labour supply, which positively impacts on the probability functions of innovation and imitation $L_{Y, i}$ (e.g., Bloom et al., 2004, show a positive effect of health on economic growth). For this purpose, we present the probabilities of innovation and imitation:

$$
\begin{gathered}
I_{N}(j, t)=y_{N}(j, t) \beta_{N} q^{k_{N}(j, t)} \zeta_{N}{ }^{-1} q^{-\alpha^{-1} k_{N}(j, t)} L_{Y, N}{ }^{\Psi}, \\
I_{S}(j, t)=y_{S}(j, t) \beta_{S} q^{k_{S}(j, t)} \frac{e^{\varphi}}{\zeta_{S} \tilde{Q}^{\sigma}} q^{-\frac{k_{N}(j, t)}{\alpha}} \frac{1}{\delta}\left(\frac{1}{\tilde{Q}}\right)^{1-\delta} L_{Y, S}{ }^{\Psi},
\end{gathered}
$$

where $y_{i}(j, t)$ is the flow of final good resources in the country $i$ allocated to R\&D in $j$, which defines our setup as a lab-equipment model (e.g., Rivera-Batiz and Romer, 1991); $\beta_{i} q^{k_{i}(j, t)}$ denotes learning by previous domestic R\&D as a favourable learning effect because of the accumulated public knowledge from previous successful R\&D (e.g., Grossman and Helpman, 1991, Ch. 12; Connolly, 2003), and we assume that $\beta_{N}>$ $\beta_{S}>0$ and $k_{N}>k_{S}$; i.e. the effect of learning-by-past innovations is higher than the learning-by-past imitations; $\zeta_{i}^{-1} q^{-\alpha^{-1} k_{N}(j, t)}$ describes the adverse effect caused by the increasing complexity of quality improvements (or the complexity cost), and it is supposed that $\zeta_{N}>\zeta_{S}$, i.e., the fixed innovation cost is higher than the fixed imitation cost (Mansfield et al., 1981); and finally, $L_{Y, i}$ denotes employment in the final-goods sector in the country $i$, with $\Psi>0$ but close to zero.

The imitation cost on $j$ also depends on the South/North ratio, $\tilde{Q}=\frac{q^{k} S^{(j, t)_{* J}}}{q^{k_{N}(j, t)_{* J}}}=$ $\frac{Q S}{Q N}=\hat{q}_{j}(\sigma>1$ refers to how fast the cost of imitation rises as the technologicalknowledge gap decreases), and on the interaction between countries ( $e^{\varphi}$ revealing lower costs of collecting information about goods from abroad with more interaction between the two economies, the interaction being measured by the ratio between Southern openness to intermediate goods imports, $M$, and the Northern technologicalknowledge level, $Q_{N}$ ). Moreover, $\delta \in[0,1]$ measures the degree of Southern IPR protection, and we introduce the IPR effect in two ways (e.g., Azevedo et al., 2014): (i) we fix a negative relationship between $\delta$ and $I_{S}(j, t)$; the higher is $\delta$, the higher is the level of Southern IPR enforcement and the lower is $I_{S}(j, t)$; (ii) we consider that the lower is the distance from the technological frontier (the greater is $\widetilde{Q}$ ), the more will IPR laws be applied by these countries and then the lower will $I_{S}(j, t)$ be, because generally, developed countries have higher levels of IPR protection (e.g., Lai and Qiu, 2003; Grossman and Lai, 2004; Naghavi, 2007; Dinopoulos and Segerstrom, 2010). 
Assuming that $L_{i}=L_{Y, i}+L_{H, i}$ and knowing that $L_{i}=l_{i}\left(h_{i}\right) N_{i}$ and $L_{H, i}=h_{i} N_{i}$, we obtain $L_{Y, i}=l_{i}\left(h_{i}\right) N_{i}-h_{i} N_{i}$ and can rewrite the probabilities as:

$$
\begin{gathered}
I_{N}(j, t)=y_{N}(j, t) \beta_{N} q^{k_{N}(j, t)} \zeta_{N}{ }^{-1} q^{-\alpha^{-1} k_{N}(j, t)}\left(N_{N}\left[l_{N}\left(h_{N}\right)-h_{N}\right]\right)^{\Psi} \\
I_{S}(j, t)=y_{S}(j, t) \beta_{S} q^{k_{S}(j, t)} \frac{e^{\varphi}}{\zeta_{S} \tilde{Q}^{\sigma}} q^{-\frac{k_{N}(j, t)}{\alpha}} \frac{1}{\delta}\left(\frac{1}{\tilde{Q}}\right)^{1-\delta}\left(N_{S}\left[l_{S}\left(h_{S}\right)-h_{S}\right]\right)^{\Psi}
\end{gathered}
$$

\section{Equilibrium}

The equilibrium conditions, namely the equilibrium $R \& D$, are similar to those described in Azevedo et al. (2014). Hence, here we underline the main essential differences.

\subsection{Equilibrium R\&D}

Bearing in mind the probabilities (29) and (30), which rely on resources (composite final goods) allocated to R\&D, entry equilibrium is defined by the equality between the expected return and the consumption of resources. In the Southern case, this equality is:

$$
I_{S}(k, j, t) V_{S}(k, j, t)=y_{S}(j, t)
$$

where $V(k, j, t)$ is the expected current value of the flow of profits to the producer of $j,{ }^{5}$ which relies on the profits at $t, \Pi_{S}(k, j, t)$, on the equilibrium interest rate and on the expected duration of the flow (i.e., expected duration of research leadership). $\Pi_{S}(k, j, t)$ relies on $M C_{N}=1, M C_{S}, P_{N N}(j), P_{N S}(j), x_{N}(k, j, t)$ and $x_{S}(k, j, t)$, and hence on trade. For instance, $I_{N}(k, j, t)$, which is the potential competitor, depends on the expected duration of the imitator's technological-knowledge leadership, as the Southern entrant competes with a Northern incumbent. Consequently, $V_{S}(k, j, t)$ is:

$$
V_{S}(k, \bar{\jmath}, t)=\int_{t}^{\infty} \Pi_{S}(k, \bar{\jmath}, t) \exp \left[-\int_{t}^{s}\left(r_{S}(v)-\gamma+I_{N}(k, \bar{\jmath}, v)\right) d v\right] d s
$$

where $\Pi_{S}(k, j, t)$, using an imitation of the quality $k$, is represented by:

$$
\Pi_{S}(k, \bar{\jmath}, t)=(1-\alpha)^{\alpha^{-1}} q^{k_{N}(j, t)(1-\alpha) \alpha^{-1}} B(t)
$$

where $B(t)=\left(1-M C_{S}\right) L_{Y, N}(t) A_{N}{ }^{-1}+\left(1+\tau_{x_{S}}-M C_{S}\right) L_{Y, S}(t)\left(A_{S} \frac{M C_{S}}{1+\tau_{x_{S}}}\right)^{\alpha^{-1}}$.

Differentiating equation (32) by applying Leibniz's rule, we achieve the dynamic arbitrage equation:

\footnotetext{
${ }^{5}$ I.e., $V(k, j, t)$ is the market value of the patent or the value of the monopolist firm, owned by consumers.
} 


$$
r_{S}(v)-\gamma+I_{N}(k, \bar{\jmath}, v)=\frac{\dot{V}_{S}(k, \bar{\jmath}, t)}{V_{S}(k, \bar{\jmath}, t)}+\frac{\Pi_{S}(k, \bar{\jmath}, t)}{V_{S}(k, \bar{\jmath}, t)}-\dot{k}(\bar{\jmath}, t)\left(\frac{1-\alpha}{\alpha}\right) \ln q
$$

If we insert (34) into the free entry R\&D equilibrium condition (31), and if we solve it for $I_{N}$, we derive the equilibrium probability of successful innovation. As the probability of successful innovation determines technological-knowledge progress, equilibrium can be translated into the path of Northern technological knowledge, from which free trade in intermediate goods allows the South to benefit as well. The relationship ends up by generating the expression, where $I_{N}$ is included, for the equilibrium growth rate of the aggregate Northern technological level, $Q_{N}$ :

$$
\hat{Q}_{N}=I_{N}\left(q^{(1-\alpha) \alpha^{-1}}-1\right)
$$

\subsection{Steady-state}

The steady-state growth rate, $g^{*}$, must be the same in both countries, since due to trade, both economies access the top intermediate goods and have the same technology of final goods production. Hence, through the Euler equation (12), interest rates as well as the term $\mu \Lambda$ are equalized in steady-state between economies, $\mu_{N} \Lambda_{N}=\mu_{S} \Lambda_{S} \equiv \mu^{*} \Lambda^{*}{ }^{6}$ Moreover, we define the instantaneous aggregate resources constraint as $Y_{S}(t)=$ $\bar{C}_{S}(t)+H_{S}+X_{S}(t)+R_{S}(t)$, where $Y_{S}(t)$ denotes total resources, the composite final good; $\bar{C}_{S}(t)$ is aggregate consumption; $H_{S}$ refers to aggregate health-care consumption; $X_{S}(t)$ represents aggregate intermediate goods; $R_{S}(t)$ is total resources employed in R\&D. That is, each aggregate final good can be consumed or saved (and used to purchase health care, for R\&D or for intermediate-goods production). Thus, the steadystate growth rate of these variables will be equal to the Northern technologicalknowledge progress. That is, the growth rate is stable and shared by both countries, $g^{*}$,

$$
g^{*}=\hat{Q}_{N}^{*}=\hat{Y}_{N}^{*}=\hat{Y}_{S}^{*}=\hat{X}_{N}^{*}=\hat{X}_{S}^{*}=\hat{R}_{N}^{*}=\hat{R}_{S}^{*}=\widehat{H}_{N}^{*}=\widehat{H}_{S}^{*}=\hat{\bar{C}}_{N}^{*}=\hat{\bar{C}}_{S}^{*}=\frac{1}{\theta}\left(r^{*}-\rho-\gamma\right)-\mu^{*} \Lambda^{*} .
$$

In particular, $\hat{\tilde{Q}}^{*}=0$ and sector shares $n_{N N}, n_{N S}$ and $n_{S}$ are constant. From (36), the Northern technological-knowledge progress is in the ascendency, while the North remains the leading innovator, though international trade and the risk of losing the

\footnotetext{
${ }^{6}$ As stated above, $\Lambda$ is constant if the aggregate capital grows at the same rate as the aggregate Northern consumption expenditures. Hence, as the mortality rate is supposed to be higher in the South (developing countries), $\mu_{N}<\mu_{S}$, the constant $\Lambda=\left(\rho+\mu_{i}\right) \frac{\mathcal{A}_{i}(t)}{\bar{C}_{i}(t) \bar{P}_{i}}$ must be higher in the North (and as $\Lambda$ also depends positively on $\mu_{i}, \Lambda_{N}>\Lambda_{S}$ implies that $\left.\frac{\mathcal{A}_{N}(t)}{\bar{C}_{N}(t) \bar{P}_{N}}>\frac{\mathcal{A}_{S}(t)}{\bar{C}_{S}(t) \bar{P}_{S}}\right)$.
} 
market for a Southern imitation infers that Northern innovation relies on Southern imitation.

In steady-state, $\frac{\dot{V}_{S}(k, \bar{J}, t)}{V_{S}(k, \bar{J}, t)}=\dot{k}(\bar{\jmath}, t)\left(\frac{1-\alpha}{\alpha}\right) \ln q$; thus, from (30), (34) becomes:

$$
I_{N}^{*}=\beta_{S} \frac{e^{\varphi}}{\zeta_{S} \delta} \tilde{Q}^{* \delta-\sigma}(1-\alpha)^{\alpha^{-1}} B^{*}\left(N_{S}\left[l_{S}\left(h_{S}\right)-h_{S}\right]\right)^{\Psi}-r^{*}+\gamma
$$

Equation (37) shows that the available (or Northern) technological knowledge:

(i) relies on innovation earnings, which in turn depend on $I_{S}$ and $\beta_{S} \frac{e^{\varphi}}{\zeta_{S} \delta} \tilde{Q}^{*}{ }^{\delta-\sigma}$, through North-South competition in intermediate goods. That is, the positive level effect from North to South (access to the top quality intermediate goods raises production and hence resources for imitation) feeds back into the North, influencing $Q_{N}$ by creative destruction;

(ii) does not depend on its scale, as it is not influenced by the stage of quality $k$. Actually, the positive effect of the quality stage on profits and on the learning effect is precisely compensated by the negative effect on the complexity cost;

(iii) relies on market-size effects;

(iv) depends on the labour employed in the Southern final goods production, $L_{Y, S}=$ $l_{S}\left(h_{S}\right) N_{S}-h_{S} N_{S}$, which in turn relies on the consumption of per capita health care, $h_{S}$. That is, the higher the Southern health care, the more available is a healthy population to produce final goods, which will have a positive impact on the resources for imitative $R \& D$, which in turn will affect Northern R\&D activity.

As far as equations (35), (36) and (37) are concerned, we can obtain the steadystate interest rate. Firstly, we consider (37) into (35) substituting $I_{N}$. Then, we use (36) into the resulting expression, substituting $\hat{Q}_{N}^{*}$ and finally, we solve this in order to $r^{*}$. Actually, as steady-state prices of non-tradable and tradable goods are constant as well as the growth rate of available technological knowledge, see (35) and (37), the steadystate interest rate shared by both countries, $r^{*}$, is:

$$
r^{*}=\frac{\left\{\beta_{S} \frac{e^{\varphi}}{\zeta_{S} \delta} \tilde{Q}^{* \delta-\sigma}(1-\alpha)^{\alpha^{-1}} B^{*} Z^{*}\right\}\left(q^{\left.(1-\alpha) \alpha^{-1}-1\right)+\frac{1}{\theta}(\rho+\gamma)}\right.}{q^{(1-\alpha) \alpha^{-1}-1+\frac{1}{\theta}}},
$$

where $Z=\left(N_{S}\left[l_{S}\left(h_{S}\right)-h_{S}\right]\right)^{\Psi}$. Considering this expression in the Euler equation, we obtain the equilibrium growth rate in the presence of population ageing:

$$
g^{*}=\frac{1}{\theta}\left[\frac{\left\{\beta_{S} \frac{e^{\varphi}}{\zeta_{S} \delta} \widetilde{Q}^{* \delta-\sigma}(1-\alpha)^{\left.\alpha^{-1} B^{*} Z^{*}\right\}\left(q^{(1-\alpha) \alpha^{-1}}-1\right)+\frac{1}{\theta}(\rho+\gamma)}\right.}{q^{(1-\alpha) \alpha^{-1}-1+\frac{1}{\theta}}}-\rho-\gamma\right]-\mu^{*} \Lambda^{*}
$$


Now, differentiating $g^{*}$ in (39) in order to $\delta$, the IPR parameter, we obtain the same sign that is obtained in the absence of population ageing by Azevedo et al. (2014). Moreover, the magnitude of the IPR effect on the growth rate remains almost the same, since despite the fact that it now depends on the term $Z^{*} . Z^{*}$ relies on $N_{S}, l_{S}, h_{S}$ and $\Psi$, as $\Psi$ is, by assumption, higher, but close to zero, $Z^{*}$ will be approximately one. Consequently, the changes in the assumptions did not change the result significantly: a negative effect of IPR protection on economic growth is found. The reason behind this negative sign can be the rise in IPR which makes imitation costly in the South and, as a result, the probability of successful imitation decreases. Through the feedback effect, this rise has also a negative effect on the steady state probability of innovation. In fact, despite the lack of consensus, there is a range in the literature which claims that the IPR effect on economic growth is not always positive.

If we differentiate $g^{*}$ in (39) with respect to $\mu^{*}$, the mortality rate, we obtain $-\Lambda^{*}+\left(-\mu^{*} \Lambda^{* \prime}\right)$. As stated above, $-\mu^{*} \Lambda^{*} \in\left[-\mu^{*}, 0\right]$, so we can show that $-\Lambda^{*} \in$ $[-1,0]$, or alternatively, $\Lambda \in[0,1]$; additionally, we know that $-\mu^{*} \Lambda^{* \prime}<0$ given that $\Lambda^{* \prime}>0$ and $-\mu^{*}<0$. Consequently, $-\Lambda^{*}+\left(-\mu^{*} \Lambda^{* \prime}\right)<0$, which enables us to conclude that when the mortality rate decreases (due for instance to an increase in per capita health care), the steady-state growth rate increases; i.e., there is a negative relationship between the mortality rate and the steady-state growth rate. As a decrease in the mortality rate means an increase in longevity, we achieve a positive effect of population ageing on the steady-state growth rate. The intuition behind this result suggests that a reduction in the mortality rate allows an expansion of the planning horizon of the agents (e.g., Prettner, 2013). Thus, individuals have more time to pay off their investments in new technologies, which leads the agents to apply less of their income to current consumption and more to investment in new technologies. However, as this demographic change has a positive effect on growth, the rise in lifetime consumption overcompensates individuals for their initial sacrifice. This positive effect is not consensual in the literature. However, works such as Prettner (2013) argue that as older people tend to save more, more resources are available for investment, having a positive effect on growth. A longer lifetime will allow investment in $R \& D$ in the future. So, the rise in lifetime will enlarge savings and the savings time span, which will foster investment, mainly in $\mathrm{R} \& \mathrm{D}$, which is commonly known as the main agent of economic growth (Aghion and Howitt, 1992). Lisenkova et al. (2012) claim there are a several 
ways by which population ageing can influence in economic growth and the macroeconomy in general. Additionally, Nagarajan et al. (2013) state the rise in the ageing population through medical improvements and the more self-centred behaviour of people influences economic growth mainly by three mechanisms: consumption and saving patterns, public social expenditure, and human capital. Bearing in mind these authors, it is more probable to find a positive impact of an ageing population on economic growth in models whose impact mechanism is 'consumption and savings patterns'. In fact, according to, for example, Li et al. (2012), it is possible to take advantage from an ageing population, namely in terms of savings, investment and economic growth rates in China.

Moreover, differentiating $g^{*}$ in (39) in order to $h$, per capita health care, bearing in mind that the mortality rate relies on the degree of per capita health and is fixed as $\mu(h)$, we obtain the following expression:

$$
\frac{\partial g^{*}}{\partial h}=\frac{1}{\theta}\left[\frac{\left\{\beta_{S} \frac{e^{\theta}}{\zeta_{S} \delta} \tilde{Q}^{* \delta-\sigma}(1-\alpha)^{\alpha^{-1}} B(t)\right\}\left(q^{(1-\alpha) \alpha^{-1}}-1\right)+\frac{1}{\theta}(\rho+\gamma)}{q^{(1-\alpha) \alpha^{-1}}-1+\frac{1}{\theta}} \psi\left(N_{S}\left[l_{S}\left(h_{S}\right)-h_{S}\right]\right)^{\psi-1} N_{S}\left(l_{S}{ }^{\prime}-1\right)-\mu^{* \prime} \Lambda^{*}\right]
$$

which will definitely be positive if $l^{\prime}(h)>1$ (given that, as mentioned above, $l^{\prime} \geq 0$ and $\mu^{\prime} \leq 0$ - i.e., the effective labour supply increases in the presence of health care improvements and the mortality rate decreases when health care is well provided). Thus, $l^{\prime}(h)>1$ is a sufficient condition for enhancing growth. This result is in line with Kuhn and Prettner (2012), since these authors point out that the growth rate rises when good health care is provided, in cases in which further supplies do not create a decline in the effective labour supply. Although the health care effect on growth is not consensual in the literature, it is possible to find evidence supporting a positive impact. The study of Bhargava et al. (2001) shows positive effects of adult survival rates (ASR) on GDP growth rates in low-income countries. For example, they find that, for the poorest nations, a $1 \%$ variation in ASR is related to an approximate $0.05 \%$ increase in growth rate. The analysis of Bloom et al. (2004) concludes that even when experience of the workforce is controlled, good health has a positive, sizable, and statistically significant influence on aggregate output. Moreover, they state that the life expectancy impact on growth regressions seems to be a real labour productivity effect, and it is not the consequence of life expectancy playing as a proxy for worker experience. These authors end their work arguing that health improvements can lead to increases in output in two ways: through labour productivity and through the accumulation of capital. Barro (2013) refers that health status, when determined by life expectancy or similar aggregate 
indicators, is a significant contributor to subsequent growth. Moreover, his results confirm not only a direct positive impact of health status on economic growth but also an indirect one, via fertility (i.e., a decrease in mortality rates would probably reduce fertility and thus improve growth). Additionally, Ngwenyama et al. (2006) find a negative impact of health on nations' development but they recognise that the conventional wisdom advocates investment in health care will enhance life expectancy which likely enhances economic development of the country.

\section{Conclusions}

The consequences of population ageing have been widely discussed in several areas of society, including as regards several economic matters such as effects on economic growth.

We developed a North-South endogenous growth model in order to understand the impact of population ageing on growth. Moreover, we aimed to understand whether, in the presence of population ageing, there is any change in the IPR effect on growth. In particular, this paper sets up a model in which there are four sectors: final-goods sector, intermediate-goods sector, $\mathrm{R} \& \mathrm{D}$ sector and health-care sector. The $\mathrm{R} \& \mathrm{D}$ sector is the main engine of endogenous growth. Perfect labour mobility is assumed between the final-goods sector and the health-care sector. The allocation of labour across these two sectors determines the effect of health care on economic growth.

Using a brief account of the literature on population ageing (and growth) as a spur motivation, we concluded that there is no consensus as to this effect. Our model also provides an explanation for the relationship between health care and economic growth both by being based on the allocation of labour across two sectors (final-goods and health-care sectors) and by reflecting on the R\&D sector the health care effect on effective labour supply, since it is expected that a healthy population is more available for work, which in turn has a positive impact on the probability of successful R\&D.

The model generates some predictions. First, relatively to Azevedo et al. (2014), population ageing does not influence the IPR effect on growth, at least in terms of sign, because the amplitude of the effect can only change marginally. Yet, the mortality rate has a negative impact on growth. Indeed, there is a positive effect of longevity on growth, which means that population ageing affects growth positively - the reason is that as the mortality rate decreases, the planning horizon of the agents increases; individuals spend less of their income on the current consumptions, and more on 
investments in new technologies because they have more time to pay off these investments. This result is not in line with those which advocate that population ageing is negative for growth, but it is in line with those that show that a positive effect of ageing on growth is possible. Moreover, the model predicts that the health-care level has a positive impact on growth when additional provisions of health do not cause a decrease in the effective labour supply, but instead increase it in a higher magnitude.

From the model assumptions and our latest findings, we can conclude that although health care raises longevity and labour supply, increases in the health-care level will enhance growth when they lead to rises in labour supply to a higher extent.

Actually, by examining empirical data, it is possible to verify that, for some groups of countries, we find the same relations we found with the model. We analysed the correlation between GDP growth (annual \%) and diverse variables and then we present some of the obtained results. Regarding the effect of longevity on growth, if we consider, for instance, data about life expectancy at birth (total, years) and GDP growth (annual \%), we find a positive correlation for Eastern European and Mediterranean countries. Alternatively, if we make an analysis in terms of income level, we find a positive correlation for low and lower middle income countries. In a similar way, if we examine carefully the relation between health expenditure (total, \% of GDP) and GDP growth (annual \%), we find a positive correlation for Mediterranean countries. Additionally, if we make the same study in terms of income level, we find a positive correlation between the referred variables for low income countries. In fact, relatively to the analysis based on income level we obtain the expected sign for the correlation between GDP growth and other variables (such as population ages 65 and above (\% of total), natural growth rate and physicians (per 1,000 people)) for low and/or middle income countries.

Also Kelley and Schmidt (2005), for instance, empirically find a positive influence of an increasing life expectancy on per capita output growth.

Regardless the above considerations, it is important to underline that one of the most interesting results of this paper is that although population ageing has no impact on the sign of the IPR effect on economic growth, population ageing and health care affect positively the steady state growth rate.

We are not able to conclude anything concrete, whether the steady-state growth rate is lower or higher when mortality is present compared to the standard case of no mortality and infinite planning horizons, because now it not only depends negatively on 
the mortality rate, but is also affected by other variables whose value is unknown and which can be negative or positive.

This analysis leaves a number of open questions. Although it allows us to conclude that there is a positive effect of both ageing population and health care on growth, this effect occurs under some conditions. Moreover, by studying merely the steady-state, our conclusions are based on comparative statics, being useful in analysing the transitional dynamics. Another interesting issue for future research is to understand the effect of growth on health-care provisions. For instance, we theoretically assume that Northern (developed) countries enjoy higher levels of health care, but these countries may not necessarily enjoy higher growth rates. It would also be useful not only to introduce health care effects by other means (besides or instead of labour), but also to make health care provisions depend on R\&D (and IPR), because higher health care provisions are associated with medical and scientific developments (as well as the fact that new drugs are often protected by IPR).

\section{Appendix}

Differentiating expressions (9) and (10) with respect to time, we obtain:

$$
\begin{gathered}
\dot{\bar{C}}_{N}(t)=\mu_{N} N_{N}\left(\int_{-\infty}^{t} \dot{\bar{c}}_{N}\left(t_{0}, t\right) e^{\mu_{N}\left(t_{0}-t\right)} d t_{0}-\mu_{N} \int_{-\infty}^{t} \bar{c}_{N}\left(t_{0}, t\right) e^{\mu_{N}\left(t_{0}-t\right)} d t_{0}\right)+\mu_{N} N_{N} \bar{c}_{N}(t, t)-0 \\
(=) \dot{\bar{C}}_{N}(t)=\mu_{N} N_{N} \bar{c}_{N}(t, t)-\mu_{N} \bar{C}_{N}(t)+\mu_{N} N_{N} \int_{-\infty}^{t} \dot{\bar{c}}_{N}\left(t_{0}, t\right) e^{-\mu_{N}\left(t-t_{0}\right)} d t_{0} \\
\dot{\mathcal{A}}_{N}(t)=\mu_{N} N_{N}\left(\int_{-\infty}^{t} \dot{a}_{N}\left(t_{0}, t\right) e^{\mu_{N}\left(t_{0}-t\right)} d t_{0}-\mu_{N} \int_{-\infty}^{t} a_{N}\left(t_{0}, t\right) e^{\mu_{N}\left(t_{0}-t\right)} d t_{0}\right)+\mu_{N} N_{N} a_{N}(t, t)-0 \\
(=) \dot{\mathcal{A}}_{N}(t)=\mu_{N} N_{N} a_{N}(t, t)-\mu_{N} \mathcal{A}_{N}(t)+\mu_{N} N_{N} \int_{-\infty}^{t} \dot{a}_{N}\left(t_{0}, t\right) e^{-\mu_{N}\left(t-t_{0}\right)} d t_{0} \\
(=) \dot{\mathcal{A}}_{N}(t)=-\mu_{N} \mathcal{A}_{N}(t)+\mu_{N} N_{N} \int_{-\infty}^{t} \dot{a}_{N}\left(t_{0}, t\right) e^{-\mu_{N}\left(t-t_{0}\right)} d t_{0} .
\end{gathered}
$$

Using the wealth constraint (4) and (42) yields:

$$
\begin{array}{r}
\dot{\mathcal{A}}_{N}(t)=-\mu_{N} \mathcal{A}_{N}(t)+\mu_{N} N_{N} \int_{-\infty}^{t}\left[\left(r_{N}+\mu_{N}-\gamma\right) a_{N}\left(t_{0}, t\right)+(1-\Gamma) w_{N}(t) l_{N}+d_{N}(t)-\bar{c}_{N}\left(t_{0}, t\right) \bar{P}_{N}-p_{H_{N}} \vartheta h_{N}\right] e^{-\mu_{N}\left(t-t_{0}\right)} d t_{0} \\
(=) \dot{\mathcal{A}}_{N}(t)=-\mu_{N} \mathcal{A}_{N}(t)+\mu_{N} N_{N} \int_{-\infty}^{t}\left(r_{N}+\mu_{N}-\gamma\right) a_{N}\left(t_{0}, t\right) e^{-\mu_{N}\left(t-t_{0}\right)} d t_{0} \\
+\mu_{N} N_{N} \int_{-\infty}^{t}(1-\Gamma) w_{N}(t) l_{N} e^{-\mu_{N}\left(t-t_{0}\right)} d t_{0}+\mu_{N} N_{N} \int_{-\infty}^{t} d_{N}(t) e^{-\mu_{N}\left(t-t_{0}\right)} d t_{0} \\
-\mu_{N} N_{N} \int_{-\infty}^{t} \bar{P}_{N} \bar{c}_{N}\left(t_{0}, t\right) e^{-\mu_{N}\left(t-t_{0}\right)} d t_{0}-\mu_{N} N_{N} \int_{-\infty}^{t} p_{H_{N}}(t) \vartheta h_{N} e^{-\mu_{N}\left(t-t_{0}\right)} d t_{0}
\end{array}
$$




$$
\begin{aligned}
& (=) \dot{\mathcal{A}}_{N}(t)=-\mu_{N} \mathcal{A}_{N}(t)+\left(r_{N}+\mu_{N}-\gamma\right) \mu_{N} N_{N} \int_{-\infty}^{t} a_{N}\left(t_{0}, t\right) e^{-\mu_{N}\left(t-t_{0}\right)} d t_{0} \\
& +(1-\Gamma) \mu_{N} N_{N} \int_{-\infty}^{t} w_{N}(t) l_{N} e^{-\mu_{N}\left(t-t_{0}\right)} d t_{0}+\mu_{N} N_{N} \int_{-\infty}^{t} d_{N}(t) e^{-\mu_{N}\left(t-t_{0}\right)} d t_{0} \\
& -\bar{P}_{N} \mu_{N} N_{N} \int_{-\infty}^{t} \bar{c}_{N}\left(t_{0}, t\right) e^{-\mu_{N}\left(t-t_{0}\right)} d t_{0}-\vartheta \mu_{N} N_{N} \int_{-\infty}^{t} p_{H_{N}}(t) h_{N} e^{-\mu_{N}\left(t-t_{0}\right)} d t_{0} \\
& (=) \dot{\mathcal{A}}(t)=-\mu \mathcal{A}(t)+\left(r_{N}+\mu-\gamma\right) \mathcal{A}(t)+(1-\Gamma) W(t)+D(t)-\bar{P}_{N} \bar{C}_{N}(t)-p_{H_{N}}(t) \vartheta H_{N} \\
& (=) \dot{\mathcal{A}}_{N}(t)=\left(r_{N}-\gamma\right) \mathcal{A}_{N}(t)+(1-\Gamma) W_{N}(t)+D_{N}(t)-\bar{P}_{N} \bar{C}_{N}(t)-p_{H_{N}}(t) \vartheta H_{N} .
\end{aligned}
$$

The above expression denotes the aggregate law of motion for capital where $W_{N}(t)=w_{N}(t) l_{N} N_{N}$ is the aggregate wage income, $D_{N}(t)=d_{N}(t) N_{N}$ represents aggregate dividend payments and $H_{N}=$ $h_{N} N_{N}$ denotes aggregate health consumption. Rewriting the individual's optimization problem subject to its lifetime budget constraint yields the following optimization problem:

$$
\begin{gathered}
\max _{\bar{c}_{N}\left(t_{0}, m\right)} U=\int_{t}^{\infty}\left(\frac{\bar{c}_{N}\left(t_{0}, m\right)^{1-\theta}-1}{1-\theta}\right) e^{\left(\rho+\mu_{N}\right)(t-m)} d m \\
\text { s.t. } a\left(t_{0}, t\right)+\int_{t}^{\infty}\left[(1-\Gamma) w_{N}(m) l_{N}+d_{N}(m)-p_{H_{N}} \vartheta h_{N}\right] e^{-\int_{t}^{m}\left(r_{N}(n)+\mu_{N}-\gamma\right) d n} d m \\
=\bar{P}_{N} \int_{t}^{\infty} \bar{c}_{N}\left(t_{0}, m\right) e^{-\int_{t}^{m}\left(r_{N}(n)+\mu_{N}-\gamma\right) d n} d m
\end{gathered}
$$

The first order condition (FOC) is

$$
\begin{gathered}
\frac{(1-\theta) \bar{c}_{N}\left(t_{0}, m\right)^{1-\theta-1}(1-\theta)}{(1-\theta)^{2}} e^{\left(\rho+\mu_{N}\right)(t-m)}-\lambda(t) \bar{P}_{N} e^{-\int_{t}^{m}\left(r_{N}(n)+\mu_{N}-\gamma\right) d n}=0 \\
(=) \bar{c}_{N}\left(t_{0}, m\right)^{-\theta} e^{\left(\rho+\mu_{N}\right)(t-m)}=\lambda(t) \bar{P}_{N} e^{-\int_{t}^{m}\left(r_{N}(n)+\mu_{N}-\gamma\right) d n} .
\end{gathered}
$$

In the period $(m=t)$ yields:

$$
\begin{gathered}
\bar{c}_{N}\left(t_{0}, t\right)^{-\theta} e^{\left(\rho+\mu_{N}\right)(t-t)}=\lambda(t) \bar{P}_{N} e^{-\int_{t}^{t}\left(r_{N}(n)+\mu_{N}-\gamma\right) d n} \\
(=) \bar{c}_{N}\left(t_{0}, t\right)^{-\theta}=\lambda(t) \bar{P}_{N} \\
(=) \bar{c}_{N}\left(t_{0}, t\right)=\left(\frac{1}{\lambda(t) \bar{P}_{N}}\right)^{\frac{1}{\theta}} \\
(=) \lambda(t)=\frac{\bar{c}_{N}\left(t_{0}, t\right)^{-\theta}}{\bar{P}_{N}}
\end{gathered}
$$

And so we can write:

$$
\begin{gathered}
\bar{c}_{N}\left(t_{0}, m\right)^{-\theta} e^{\left(\rho+\mu_{N}\right)(t-m)}=\frac{\bar{c}_{N}\left(t_{0}, t\right)^{-\theta}}{\bar{P}_{N}} \bar{P}_{N} e^{-\int_{t}^{m}\left(r_{N}(n)+\mu_{N}-\gamma\right) d n} \\
(=) \bar{c}_{N}\left(t_{0}, t\right)^{\theta} e^{\left(\rho+\mu_{N}\right)(t-m)}=\bar{c}_{N}\left(t_{0}, m\right)^{\theta} e^{-\int_{t}^{m}\left(r_{N}(n)+\mu_{N}-\gamma\right) d n} \\
(=) \bar{c}_{N}\left(t_{0}, t\right) e^{\left(\rho+\mu_{N}\right)(t-m)}=\bar{c}_{N}\left(t_{0}, m\right) e^{-\int_{t}^{m}\left(r_{N}(n)+\mu_{N}-\gamma\right) d n}
\end{gathered}
$$

If we integrate the previous expression, and use the budget constraint given in the optimization problem (43), we have:

$$
\begin{gathered}
\int_{t}^{\infty} \bar{c}_{N}\left(t_{0}, t\right) e^{\left(\rho+\mu_{N}\right)(t-m)} d m=\int_{t}^{\infty} \bar{c}_{N}\left(t_{0}, m\right) e^{-\int_{t}^{m}\left(r_{N}(n)+\mu_{N}-\gamma\right) d n} d m \\
(=) \int_{t}^{\infty} \bar{c}_{N}\left(t_{0}, t\right) e^{\left(\rho+\mu_{N}\right)(t-m)} d m=\frac{1}{\bar{P}_{N}}\left\{a\left(t_{0}, t\right)+\int_{t}^{\infty}\left[(1-\Gamma) w_{N}(m) l_{N}+d_{N}(m)-p_{H_{N}} \vartheta h_{N}\right] e^{-\int_{t}^{m}\left(r_{N}(n)+\mu_{N}-\gamma\right) d n} d m\right\} .
\end{gathered}
$$

Additionally, if we consider: 


$$
\omega_{N}(t)=\int_{t}^{\infty}\left[(1-\Gamma) w_{N}(m) l_{N}+d_{N}(m)-p_{H_{N}} \vartheta h_{N}\right] e^{-\int_{t}^{m}\left(r_{N}(n)+\mu_{N}-\gamma\right) d n} d m,
$$

we can rewrite the expression as,

$$
\begin{aligned}
& \int_{t}^{\infty} \bar{c}_{N}\left(t_{0}, t\right) e^{\left(\rho+\mu_{N}\right)(t-m)} d m=\frac{1}{\bar{P}_{N}}\left[a_{N}\left(t_{0}, t\right)+\omega_{N}(t)\right] \\
& (=) \frac{\bar{c}_{N}\left(t_{0}, t\right)}{\rho+\mu_{N}}\left[-e^{\left(\rho+\mu_{N}\right)(t-m)}\right]_{t}^{\infty}=\frac{1}{\bar{P}_{N}}\left[a\left(t_{0}, t\right)+\omega(t)\right] \\
& (=) \bar{c}_{N}\left(t_{0}, t\right)=\frac{1}{\bar{P}_{N}}\left(\rho+\mu_{N}\right)\left[a_{N}\left(t_{0}, t\right)+\omega_{N}(t)\right]
\end{aligned}
$$

or equivalently,

$$
\begin{gathered}
\bar{c}_{N}\left(t_{0}, t\right) \bar{P}_{N}=\left(\rho+\mu_{N}\right)\left[a_{N}\left(t_{0}, t\right)+\omega_{N}(t)\right] \\
(=) \operatorname{expend}_{N}\left(t_{0}, t\right)=\left(\rho+\mu_{N}\right)\left[a_{N}\left(t_{0}, t\right)+\omega_{N}(t)\right],
\end{gathered}
$$

$\omega_{N}(t)$ denotes the human wealth of agents which depends on lifetime income of wages and dividends net of taxes and private health payments. According to Kuhn and Prettner (2012), human wealth does not depend on one's date of birth because lump-sum dividends are assumed and productivity is supposed to be age independent. Hence, in our case, optimal consumption expenditure in the planning period is proportional to total wealth with a marginal propensity to expend of $\left(\rho+\mu_{N}\right)$. Bearing in mind this and the expression at (10), it is possible to find an expression for the evolution of aggregate consumption:

$$
\begin{gathered}
\bar{C}_{N}(t) \equiv \mu_{N} N_{N} \int_{-\infty}^{t} \bar{c}_{N}\left(t_{0}, t\right) e^{\mu_{N}\left(t_{0}-t\right)} d t_{0} \\
(=) \bar{C}_{N}(t)=\mu_{N} N_{N} \int_{-\infty}^{t}\left(\frac{\left(\rho+\mu_{N}\right)\left[a_{N}\left(t_{0}, t\right)+\omega_{N}(t)\right]}{\bar{P}_{N}}\right) e^{\mu_{N}\left(t_{0}-t\right)} d t_{0} \\
(=) \bar{C}_{N}(t)=\frac{1}{\bar{P}_{N}}\left(\rho+\mu_{N}\right)\left(\mu_{N} N_{N} \int_{-\infty}^{t} a_{N}\left(t_{0}, t\right) e^{\mu_{N}\left(t_{0}-t\right)} d t_{0}+\mu_{N} N_{N} \int_{-\infty}^{t} \omega_{N}(t) e^{\mu_{N}\left(t_{0}-t\right)} d t_{0}\right) \\
(=) \bar{C}_{N}(t)=\frac{1}{\bar{P}_{N}}\left(\rho+\mu_{N}\right)\left(\mathcal{A}_{N}\left(t_{0}, t\right)+\Omega_{N}(t)\right)
\end{gathered}
$$

or, equivalently,

$$
\begin{aligned}
\bar{C}_{N}(t) \bar{P}_{N} & =\left(\rho+\mu_{N}\right)\left(\mathcal{A}_{N}\left(t_{0}, t\right)+\Omega_{N}(t)\right) \\
(=) E_{N}(t) & =\left(\rho+\mu_{N}\right)\left(\mathcal{A}_{N}\left(t_{0}, t\right)+\Omega_{N}(t)\right),
\end{aligned}
$$

where $\Omega_{N}(t)$ denotes the Northern aggregate human wealth. As newborns do not own capital because there are no bequests,

$$
\begin{aligned}
& \bar{C}_{N}(t, t)=\frac{1}{\bar{P}_{N}}\left(\rho+\mu_{N}\right) \omega_{N}(t) \\
& \bar{C}_{N}(t, t)=\frac{1}{\bar{P}_{N}}\left(\rho+\mu_{N}\right) \Omega_{N}(t)
\end{aligned}
$$

holds for each newborn individual and each newborn cohort, respectively. By putting equations (6), (41), (45), (46) and (47) together, we obtain:

$$
\dot{\bar{C}}_{N}(t)=\mu_{N} N_{N} \bar{c}_{N}(t, t)-\mu_{N} \bar{C}_{N}(t)+\mu_{N} N_{N} \int_{-\infty}^{t} \dot{\bar{c}}_{N}\left(t_{0}, t\right) e^{-\mu_{N}\left(t-t_{0}\right)} d t_{0}
$$




$$
\begin{aligned}
& (=) \dot{\bar{C}}_{N}(t)=\mu_{N} N_{N} \frac{1}{\bar{P}_{N}}\left(\rho+\mu_{N}\right) \omega_{N}-\mu_{N}\left[\frac{1}{\bar{P}_{N}}\left(\rho+\mu_{N}\right)\left(\mathcal{A}_{N}\left(t_{0}, t\right)+\right) \Omega_{N}(t)\right] \\
& +\mu_{N} N_{N} \int_{-\infty}^{t} \frac{1}{\theta}\left(r_{N}-\gamma-\frac{\dot{\bar{P}}_{N}}{\bar{P}_{N}}-\rho\right) \bar{c}_{N}\left(t_{0}, t\right) e^{-\mu_{N}\left(t-t_{0}\right)} d t_{0} \\
& (=) \dot{\bar{C}_{N}}(t)=\frac{1}{\bar{P}_{N}} \mu_{N}\left(\rho+\mu_{N}\right) \Omega_{N}(t)-\frac{1}{\bar{P}_{N}} \mu_{N}\left(\rho+\mu_{N}\right) \mathcal{A}_{N}\left(t_{0}, t\right)-\frac{1}{\bar{P}_{N}} \mu_{N}\left(\rho+\mu_{N}\right) \Omega_{N}(t) \\
& +\frac{1}{\theta}\left(r_{N}-\gamma-\frac{\dot{\bar{P}}_{N}}{\bar{P}_{N}}-\rho\right) \mu_{N} N_{N} \int_{-\infty}^{t} \bar{c}_{N}\left(t_{0}, t\right) e^{-\mu_{N}\left(t-t_{0}\right)} d t_{0} \\
& (=) \dot{\bar{C}_{N}}(t)=\frac{1}{\bar{P}_{N}} \mu_{N}\left(\rho+\mu_{N}\right) \Omega_{N}(t)-\frac{1}{\bar{P}_{N}} \mu_{N}\left(\rho+\mu_{N}\right) \mathcal{A}_{N}\left(t_{0}, t\right)-\frac{1}{\bar{P}_{N}} \mu_{N}\left(\rho+\mu_{N}\right) \Omega_{N}(t) \\
& +\frac{1}{\theta}\left(r_{N}-\gamma-\frac{\dot{\bar{P}}_{N}}{\overline{\bar{P}}_{N}}-\rho\right) \bar{C}_{N}(t) \\
& \dot{\bar{C}_{N}}(t)=-\frac{1}{\bar{P}_{N}} \mu_{N}\left(\rho+\mu_{N}\right) \mathcal{A}_{N}\left(t_{0}, t\right)+\frac{1}{\theta}\left(r_{N}-\gamma-\frac{\dot{\bar{P}}_{N}}{\bar{P}_{N}}-\rho\right) \bar{C}_{N}(t) .
\end{aligned}
$$

And then,

$$
\begin{gathered}
\frac{\dot{\bar{C}_{N}}(t)}{\overline{\bar{C}}_{N}(t)}=-\mu_{N}\left(\rho+\mu_{N}\right) \frac{\mathcal{A}_{N}\left(t_{0}, t\right)}{\bar{C}_{N}(t) \bar{P}_{N}}+\frac{1}{\theta}\left(r_{N}-\gamma-\frac{\dot{\bar{P}}_{N}}{\bar{P}_{N}}-\rho\right) \frac{\bar{C}_{N}(t)}{\bar{C}_{N}(t)} \\
(=) \frac{\dot{\bar{C}_{N}}(t)}{\bar{C}_{N}(t)}=-\mu_{N}\left(\rho+\mu_{N}\right) \frac{\mathcal{A}_{N}\left(t_{0}, t\right)}{\bar{C}_{N}(t) \bar{P}_{N}}+\frac{1}{\theta}\left(r_{N}-\gamma-\frac{\dot{\bar{P}}_{N}}{\bar{P}_{N}}-\rho\right) .
\end{gathered}
$$

As $\bar{C}_{N}(t)=\frac{1}{\bar{P}_{N}}\left(\rho+\mu_{N}\right)\left(\mathcal{A}_{N}\left(t_{0}, t\right)+\Omega_{N}(t)\right)$,

$$
\begin{gathered}
\left(\rho+\mu_{N}\right) \mathcal{A}_{N}\left(t_{0}, t\right)=\bar{C}_{N}(t) \bar{P}_{N}-\left(\rho+\mu_{N}\right) \Omega_{N}(t) \\
(=)\left(\rho+\mu_{N}\right) \mathcal{A}_{N}\left(t_{0}, t\right)=\bar{C}_{N}(t) \bar{P}_{N}-\bar{C}_{N}(t, t) \bar{P}_{N}, \\
\frac{\dot{C}_{N}(t)}{\bar{C}_{N}(t)}=-\mu_{N}\left(\frac{\bar{C}_{N}(t) \bar{P}_{N}-\bar{C}_{N}(t, t) \bar{P}_{N}}{\bar{C}_{N}(t) \bar{P}_{N}}\right)+\frac{1}{\theta}\left(r_{N}-\gamma-\frac{\dot{\bar{P}}_{N}}{\bar{P}_{N}}-\rho\right) \\
(=) \frac{\dot{\bar{C}}_{N}(t)}{\bar{C}_{N}(t)}=-\mu_{N}\left(\frac{\bar{C}_{N}(t) \bar{P}_{N}-\bar{C}_{N}(t, t) \bar{P}_{N}}{\bar{C}_{N}(t) \bar{P}_{N}}\right)+\frac{1}{\theta}\left(r_{N}-\gamma-\frac{\dot{\bar{P}}_{N}}{\bar{P}_{N}}-\rho\right) \\
(=) \frac{\dot{C}_{N}(t)}{\bar{C}_{N}(t)}=-\mu_{N}\left(\frac{\overline{\bar{C}}_{N}(t)-\bar{C}_{N}(t, t)}{\bar{C}_{N}(t)}\right)+\frac{1}{\theta}\left(r_{N}-\gamma-\frac{\dot{P}_{N}}{\bar{P}_{N}}-\rho\right)
\end{gathered}
$$

rearranging,

$$
\frac{\dot{\bar{C}}_{N}(t)}{\bar{C}_{N}(t)}=\frac{1}{\theta}\left(r_{N}-\gamma-\frac{\dot{\bar{P}}_{N}}{\bar{P}_{N}}-\rho\right)-\mu_{N}\left(\frac{\bar{C}_{N}(t)-\bar{C}_{N}(t, t)}{\bar{C}_{N}(t)}\right),
$$

which is the aggregate Euler equation. This equation is different from the individual Euler equation due to the term $-\mu_{N}\left(\frac{\bar{c}_{N}(t)-\bar{C}_{N}(t, t)}{\bar{C}_{N}(t)}\right) \in\left[-\mu_{N}, 0\right]$.

\section{References}

Aghion, P. and Howitt, P. (1992). 'A model of growth through creative destruction.' Econometrica, 60(2), pp. 323-352. 
Azevedo, M., Afonso, O. and Silva, S. (2014). "Endogenous growth and intellectual property rights: a North-South modelling proposal.” Economic Modelling, 38, pp. 112-120.

Barro, R. (2013). 'Health and economic growth.' Annals of Economics and Finance, 14 (2A), pp. 305-342.

Bhargava, A., Jamison, D., Lau, L. and Murray, C. (2001). 'Modeling the effects of health on economic growth.' Journal of Health Economics, 20, pp. 423-440.

Blanchard, O. (1985). 'Debt, deficits and finite horizons.' Journal of Political Economy, 93(2), pp. 223-247.

Bloom, D., Börsch-Supan, A., McGee, P. and Seike, A. (2011). 'Population aging: facts, challenges, and responses', Working Paper n. 71, Program on the Global Demography of Aging.

Bloom, D., Canning, D. and Sevilla, J. (2004). 'The effect of health on economic growth: a production function approach.' World Development, 32(1), pp. 1-13.

Bloom, D., Canning, D. and Fink, G. (2008). 'Population aging and economic growth.' Working Paper n. 32, The World Bank Commission on Growth and Development.

Bloom, D., Canning, D. and Fink, G. (2010a). 'The graying of global population and its macroeconomic consequences.' The WDA-HSG Discussion Paper Series on Demographic Issues, n. 2010/4.

Bloom, D., Canning, D. and Fink, G. (2010b). 'Implications of population ageing for economic growth.' Oxford Review of Economic Policy, 26(4), pp. 583-612.

Bongaarts, J. and Sobotka, T. (2012). 'A demographic explanation for the recent rise in the European fertility.' Population and Development Review, 38(1), pp. 83-120.

Branstetter, Lee, Fisman, Ray, Foley, Fritz and Saggi, Kamal, (2007). 'Intellectual property rights, imitation, and foreign direct investment: theory and evidence.' Southern Methodist University, Mimeo.

Cervellati, M. and Sunde, U. (2005). 'Human capital formation, life expectancy, and the process of development.' American Economic Review, 95(5), pp. 1653-1672.

Connolly, M. (2003). 'The dual nature of trade: measuring its impact on imitation and growth.' Journal of Development Economics, 72(1), pp. 31-55.

Connolly, M. and Valderrama, D. (2005). 'North-South technological diffusion: a new case for dynamic gains from trade.' Working Paper, Federal Reserve Bank of San Francisco.

Cutler, D., Deaton, A. and Lleras-Muney, A. (2006). 'The determinants of mortality.' Journal of Economic Perspectives, 20(3), pp. 97-120.

Dinopoulos, E. and Segerstrom, P. (2010). 'Intellectual property rights, multinational firms and economic growth.' Journal of Development Economics, 92, pp. 13-27.

Eiras, G. and Niepelt, D. (2012). 'Ageing, government budgets, retirement and growth.' European Economic Review, 56, pp. 97-115. 
Falvey, R., Foster, N. and Greenaway, D. (2006). 'Intellectual property rights and economic growth.' Review of Development Economics, 10(4), pp. 700-719.

Glass, A. J. and Saggi, K. (2002). 'Intellectual property rights and foreign direct investment.' Journal of International Economics, 56, pp. 387-410.

Glass, A. J. and Wu, X. (2007). 'Intellectual property rights and quality improvement.' Journal of Development Economics, 82, pp. 393-415.

Groezen, B., Meijdam, L. and Verbon, H. (2005). 'Serving the old: ageing and economic growth.' Oxford Economic Papers, 57, pp. 647-663.

Grossman, G. and Helpman, E. (1991). Innovation and Growth in the Global Economy, MIT Press, Cambridge, MA.

Grossman, G. and Lai, E. (2004). 'International protection of intellectual property.' American Economic Review, 94, pp. 1635-1653.

Harper, S. and Leeson, G. (2009). 'Introducing the Journal of population Ageing.' Journal Population ageing, 1, pp. 1-5.

Hazan, M. and Zoabi, H. (2006). 'Does longevity cause growth? A theoretical critique.' Journal of Economic Growth, 11(4), pp. 363-376.

Hall, B. H. and Rosenberg, N. (2010). Handbook of the Economics of Innovation, Elsevier: Amsterdam.

Heijdra, B. and van der Ploeg, F. (2002). The Foundations of modern macroeconomics, Oxford University Press, Oxford.

Kelley, A. C. and Schmidt, R. M. (2005). 'Evolution of recent economic-demographic modeling: A synthesis.' Journal of Population Economics, 18(2), pp. 275-300.

Kuhn, M. and Prettner, K. (2012). 'Growth and welfare effects of health care in knowledge based economies.' Discussion Paper n. 120, Courant Research Centre: Poverty, Equity and Growth.

Lai, E. (1998). 'International intellectual property rights protection and the rate of product innovation,' Journal of Development Economics, 55, pp. 133-153.

Lai, E., and Qiu, L. (2003). 'The North's intellectual property rights standard for the South?' Journal of International Economics, 59, pp. 183-209.

Lee, S., Mason, A. and Park, D. (2011). 'Why does population aging matter so much for Asia? Population aging, economic security and economic growth in Asia.' ERIA Discussion Paper Series, ERIA-DP-2011-04.

Lichtenberg, F. (2004). 'Sources of U.S. longevity increase, 1960-2001.' Quarterly Review of Economics and Finance, 44, pp. 369-389.

Lindh, T. and Malmberg, B. (2009). 'European Union economic growth and the age structure of the population.' Economic Change and Restructuring, 42(3), pp. 159-187. 
Lisenkova, K., Mérette, M. and Wright, R. (2012). 'The Impact of Population Ageing on the Labour Market: Evidence from Overlapping Generations Computable General Equilibrium (OLG-CGE) Model of Scotland.' SIRE Discussion Paper, SIRE-DP-201190.

Mansfield, E., Swartz, M. and Wagner, S. (1981). 'Imitation costs and patents: an empirical study.' Economic Journal, 91(364), pp. 907-918.

Mason, A. and Lee, R., (2011). 'Population aging and the generational economy: key findings.' In Population aging and generational economy project, A global perspective, R. Lee and A. Mason (editors), Cheltenham, UK, and Northampton, MA, USA: Edward Elgar, pp. 331.

Nagarajan, R., Teixeira, A. and Silva, S. (2013). 'The impact of an ageing population on economic growth: an explanatory review of the main mechanisms.' Working Paper n. 504, FEP.

Naghavi, A. (2007). 'Strategic intellectual property rights policy and North-South technology transfer.' Review of World Economics, 143(1), pp. 55-78.

Narciso, A. (2010). 'The impact of population ageing on international capital flows.' MPRA Paper n. 26457.

Ngwenyama, O., Andoh-Baidoo, F. K., Bollou, F., \& Morawczynski, O. (2006). 'Is there a relationship between ICT, health, education and development? An empirical analysis of five West African Countries from 1997-2003.' The Electronic Journal of Information Systems in Developing Countries, 23(5), pp. 1-11.

Panagopoulos, A. (2009). 'Revisiting the link between knowledge spillovers and growth: an intellectual property perspective', Economics of Innovation and New Technology, 18(6), pp. 533-546.

Papageorgiou, C. (2002). 'Technology adoption, human capital, and growth theory.' Review of Development Economics, 6(3), pp. 351-368.

Park, W. G. and Ginarte, J. C. (1997). 'Intellectual property rights and economic growth.' Contemporary Economic Policy, XV, pp. 51-61.

Prettner, K. (2013). 'Population aging and endogenous economic growth.' Journal of Population Economics, 26, pp. 811-834.

Rivera-Batiz, L. and Romer, P. (1991). 'Economic integration and endogenous growth.' Quarterly Journal of Economics, 106(2), pp. 531-555.

Romer, P. (1990). 'Endogenous technological change.' Journal of Political Economy, 98(5), pp. S71-S102.

Sener, F. (2006). 'Intellectual property rights and rent protection in a North-South product cycle model.' Union College, Mimeo. 
The Economist (2009). 'A special report on ageing populations.' The Economist, 27 June 2009, http://www.economist.com/node/13888045, accessed in December, 2013.

The Economist (2011). '70 or bust! Why the retirement age must go up. A special report on pensions.' The Economist, 7 April 2011, http://www.economist.com/node/18529505, accessed in December, 2013.

Walder, B. and Döring, T., (2012). 'The Effect of Population Ageing on Private Consumption A Simulation for Austria based on Household Data up to 2050.' Eurasian Economic Review, 2(1), pp. 63-80. 